\title{
Application of sago pith waste and nanosilica from rice husk ash as hybrid bio-nanofiller composite for food plastic packaging
}

\author{
Asriadi Masnar ${ }^{1}$, Ranil Coorey \\ 1 - Hasanuddin University, Makassar, Indonesia \\ 2 - Curtin University of Technology, Perth, Australia
}

\section{Keywords: \\ Nanofiller \\ Food \\ Packaging, \\ Bioplastic \\ Sago pith \\ Waste}

\section{Article history:}

Received 14.11.2017

Received in revised form 25.12.2017

Accepted 29.12.2017

Corresponding

author:

Asriadi Masnar

E-mail:

asriadi.masnar@

postgrad.curtin.edu.au

DOI: $10.24263 / 2304-$

974X-2017-6-4-4

\section{Abstract}

Introduction. Agricultural wastes such as Rice Husk Ash from rice (Oryza sativa) (RHA) and Sago Pith (Metroxylon sago sp.) (SP) wasted in thousand ton every harvest season. Both waste contain relatively high in silica and cellulose accordingly that can be utilized as biocomposites for degradable plastic.

Materials and methods. Nanosilica from RHA was obtained through sol-gel method and SP was refined through acid washing method. The experiment performed through pressure test, water immersion and heat absorbtion through microwave.

Results and discussion. The formulated sample has crosslinking of the hybrid filler with the PLA (Polylactic Acid) matrix which effectively improves hardness and density properties in PLA (amount 61\%). This is found in combination of nanosilica, SPW fibre and PLA (60:20:20). In the water absorbtion test, the modified samples indicates insignificant water-resistant behaviour with effective combination silica : SPW fiber amount 20:10. This combination has complex barrier that inhibiting water molecule to infiltrate into the matrix compound. During heat exposure test, all modified biocomposites sample shown higher temperature than standart PLA yet the value is less significant. However, this might have been caused by the nanosilica composite exhibited an excellent thermal insulation and slow thermal desorption during thermal exposure that be accumulated in the polymer matrix and distributes higher temperature in modified biocomposites than pure PLA.

Conclusions. Although still need further research for safety aspect, this found shows high potential possibility of agricultural wastes generated as eco-friendly food and beverages packaging. Furthermore, this hybrid composite is able to reduce the usage of common plastics and styrofoam as container due to similarity shared by this composite in terms of common plastic physical and chemical characteristics. 


\section{Introduction}

Substitutions for plastic composite have been the subject of rapid expansion in the development and application of food packaging recently [1-3]. However, the primary drawback of using fillers or composites as the reinforcement lies in the poor interfacial adhesion between hydrophilic composite materials and hydrophobic plastics, which results in poor mechanical properties of the final composites. Improvement of bonding interaction between matrix and composites can be achieved by modifying the filler-plastics surface.

Globally, 480 million metric tons of milled rice is produced each year, which contain 96 million metric tons of husks $(20 \%)[4,5]$. After completely burning these husks at 700 ${ }^{\circ} \mathrm{C}$ for $6 \mathrm{~h}$ Rice Husk Ash (RHA) contains more than $90 \%$ of silica [6,7]. Silica exists as a polymer in the form of $\mathrm{SiO}_{2}$ then joining together to form the complex compound $\left(\mathrm{SiO}_{4}\right)$. Silica is widely used as a catalyst, filler, adsorbents, and gases separator. To increase the mechanical properties such as strength, durability and thermal stability, silica is converted to nano size that also make silica particle evenly distributed. Several techniques have been founded to prepare nanosilica yet the most common method is through sol-gel method $[8,9]$.

The research of renewable resource has been developed and continues to emerge the making of bio-plastic material especially for production organic-inorganic hybrids types driven by petroleum resources depletion and global warming. Both sago pith and rice husk ash are available in huge quantity and has almost no to very low commercial value in raw condition $[10,11]$. The hybrid component of organic-inorganic research is now gaining a wide interest along with nanotechnology application since it poses significant improvement of mechanical properties [12] such as improve strength, thermal stability, gases barrier characteristic, resistance to solvent, adhesive force, and controlled gradient properties [13] . Generally there are three methods to synthetize Nano-scale material with identical size i.e.: sol-gel, layered organic-inorganic assembly and bio-mineralization method [14, 15].

Food packaging is aimed to avoid potential contaminations of food, maintain the food quality, and extend food shelf life [16, 17] by preventing moisture access, oxidation or microbial contamination [18]. In fact, synthetic plastics made from petroleum are still extensively used as food packaging materials due to the endurance, stability, clearance, and low weight as its attractive factors [19-21]. However, plastic packaging poses high potential hazards to the human's health [22], wildlife and environment regarding degradability which took thousand years to be destroyed [23-26]. During recent years, many biomass and agricultural derived materials have been developed to be composite of degradable polymers, polylactic acid, and bio-thermoplastic due to its lower risk, low cost, abundant sources, inherent biodegradability and eco friendly material [27, 28].

The development of sol-gel chemistry was started during nuclear industry era in the $19^{\text {th }}$ century involved preparation of alkoxide compound from SiCl4 [29]. Solid oxide material can be obtained in Nano-scale from sol-gel method by experiencing several chemical alterations from liquid as a sol phase into gel formation $[30,31]$. This method gain popularity among scientists since it can be performed under relative low temperature and generates solid pure oxide material with even uniform size [32-34]. The report on hybrid packaging material for food packaging is still very limited. Hence, this study is aimed to develop hybrid Nano filler biodegradable plastic that can be safely applied for food packaging and as replacements for conventional plastics. 


\section{Materials and methods}

\section{Materials}

Sago waste pith used in this research was obtained locally from Pentojangan village, South Sulawesi, Indonesia. Rice Husk Ash (RHA) was be supplied from local market in Makassar Indonesia. Reagent grade glycerol, Poly Lactic Acid (PLA) was purchased from NatureWorks LLC, (Minnetonka, Minnesota, United States ) and n-butanol was purchased from Sigma-Aldrich Co (NSW Australia). $\mathrm{HCl}, \mathrm{NaOH}, \mathrm{H}_{2} \mathrm{SO}_{4}$ purchased from Merck Millipore (VIC, Australia).

\section{Preparation of composites}

Preparation of High Refined Cellulose (HRC) from Sago Pith waste (SPW). The collection of the pith followed the method by Abral, Putra [11] by cleaning the fibers with water several times to remove undesired materials and subsequently dehumidified for 48 hours to obtain the sago pith as a fiber for further processing of HRC .

The chemical pretreatment of sago pith waste was conducted as per the methods by Supratno, Tawfiequrrahman, \& Yunanto, (2013) [35]. The method initated by adding the delignification agent of $\mathrm{HNO}_{3}, \mathrm{NaOH}$ and $\mathrm{H}_{2} \mathrm{O}_{2}$ to remove undesired materials and obtain Highly Refined Cellulose (HRC) product. The nitric acid concentration of 4,5\%, sodium hydroxide concentration of $2 \mathrm{~N}$, hydrogen peroxide concentration of $3,5 \%$ is the optimal condition of the delignification process of Sago wood fiber [35]. The experiments carried out in a $1000 \mathrm{~mL}$ (Brand ${ }^{\circledR}$ glass beaker with spout, low form, Sigma-Aldrich Pty Ltd Australia, NSW, Castle Hill), stirring rods (Aldrich ${ }^{\circledR}$ stirring rods, Australia, NSW, Castle Hill) and thermometer (Easy-Read ${ }^{\circledR}$ thermometer, Australia, NSW, Castle Hill). Threesteps atmospheric processes was involved, first addition of nitric acid solution at $80{ }^{\circ} \mathrm{C}$ for 2 hours, then the second step using sodium hydroxide at $80{ }^{\circ} \mathrm{C}$ for 2 hours and finishing using hydrogen peroxide at $80{ }^{\circ} \mathrm{C}$ for $30-300 \mathrm{~min}$ as the final step as shown in Figure 1 [36].

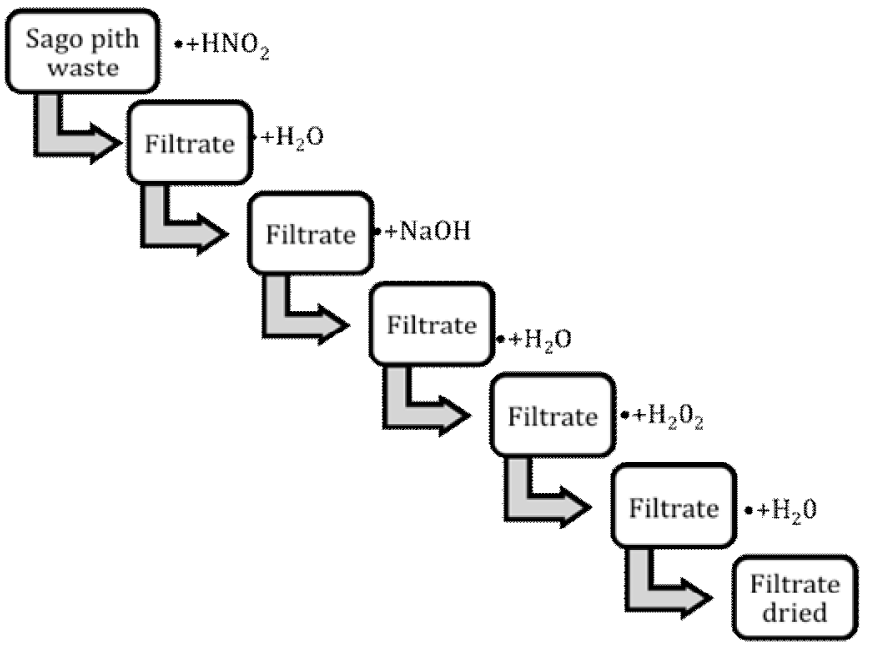

Figure 1. Preparation of high refined cellulose (HRC) from sago pith waste (SPW) 
Preparation of nanosilica. Silica nano particles were prepared as per Livage, Henry, \& Sanchez and as modified by Sindoro, Yanai, Jee, \& Granick, [8]. Pretreatment of the RHA (Steps 1-3) and preparation of silica nanoparticles synthesis (4-5) can be shown on Figure 2.

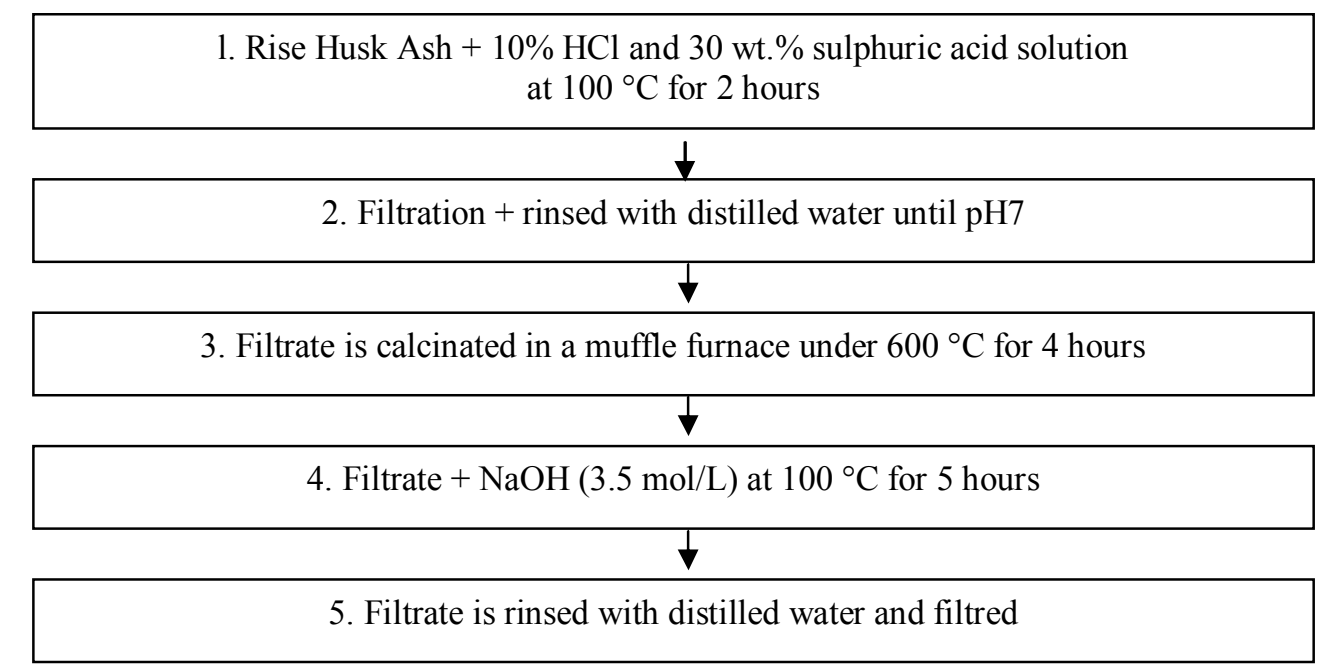

Figure 2. Preparation of nanosilica

Pretreatment of the RHA. In order to remove assimilated hydrocarbons, RHA is treated with $10 \%$ chloric acid and percolated with $30 \mathrm{wt} . \% \mathrm{H}_{2} \mathrm{SO}_{4}$ at $100{ }^{\circ} \mathrm{C}$ for 2 hours. The result is filtered and rinsed with distilled water until reaching neutral $\mathrm{pH}$ prior to calcination in a muffle furnace under $600^{\circ} \mathrm{C}$ for 4 hours [5].

\section{Synthesis of silica nanoparticles}

The synthesis followed the method by Liou and Yang [37] i.e. $100 \mathrm{gr}$ silica/carbon powder was added to a flask containing a $1.5 \mathrm{M}$ sodium hydroxide $(\mathrm{NaOH})$ solution (Merck $\& \mathrm{Co}$.). The sample was then boiled at $100{ }^{\circ} \mathrm{C}$ for $1 \mathrm{~h}$ with constant stirring, thus converting silica into a sodium silicate solution. The solution was centrifuged (Corning ${ }^{\circledR}$ LSE $^{\mathrm{TM}}$ compact centrifuges, Australia, NSW, Castle Hill) to remove carbon solids and filtered using a glass filter Grade GF/F circles, $25 \mathrm{~mm}$ (Whatman plc, England) to remove small quantities of metal and carbon residues. The filtration process was repeated several times to obtain a clear and colorless solution. Deionized water was used to dilute the solution to 1.0 M. The sodium silicate then neutralized with hydrochloric $(\mathrm{HCl})$. The sodium silicate solution was titrated slowly to the $1.0 \mathrm{M}$ acid solution and, to avoid local changes in $\mathrm{pH}$ during gel formation. The mixture was stirred at a constant rate inside the beaker. The solution monitored with a $\mathrm{pH}$ meter to control $\mathrm{pH}$ at a constant value of 3-11. After acidification, aquagels were transferred into closed plastic vessels and allowed to age at a constant room temperature $\left(24-26^{\circ} \mathrm{C}\right)$ for $1-96 \mathrm{~h}$. Deionized water was added to the gels. The gel was then centrifuged to remove solute salts. The washing step was repeated, and the solids were collected and dried at $80{ }^{\circ} \mathrm{C}$ for $48 \mathrm{~h}$. Therefore, the following calculation can be used for extracting silica yield from (RHA): 


$$
\begin{aligned}
& - \text { Food Technology- } \\
& (\%) \text { Silica extraction yield }=\frac{\text { Mass of produced silica }}{\text { Mass of carbonized husk } \cdot 0.5015} \cdot 100
\end{aligned}
$$

\section{Making of hybrid bio-nanofiller degradable plastic}

After preparation of high refined cellulose of Sago Pith Waste and nano silica, both materials will be formulated into five samples combined with Polilactic Acid (PLA) and Glycerine. Each sample combination of these natural based compound can be seen on table 1.

Table 1 Combination of nano-silica, sago pith and plasticizer

\begin{tabular}{|c|c|c|}
\hline Sample & Composition & Volume (\%) \\
\hline \multirow{3}{*}{$\mathrm{A}$} & PLA & 60 \\
\cline { 2 - 3 } & Nano silica & 20 \\
\cline { 2 - 3 } & SPW & 20 \\
\hline \multirow{3}{*}{$\mathrm{B}$} & PLA & 70 \\
\cline { 2 - 3 } & Nano silica & 20 \\
\cline { 2 - 3 } & SPW & 10 \\
\hline \multirow{4}{*}{$\mathrm{C}$} & PLA & 70 \\
\cline { 2 - 3 } & Nano silica & 10 \\
\cline { 2 - 3 } & SPW & 20 \\
\hline \multirow{2}{*}{$\mathrm{D}$} & PLA & 65 \\
\cline { 2 - 3 } & Nano silica & 15 \\
\cline { 2 - 3 } & SPW & 15 \\
\hline E & PLA (control) & 100 \\
\hline
\end{tabular}

The sample combinations will be mixed by using magnetic stirrer with stainless steel heating plate (RH Basic 2, IKA, Germany) at $100{ }^{\circ} \mathrm{C}$, within $1700-2,000 \mathrm{rpm}$ for 10 minutes in the beaker $100 \mathrm{ml}$. The process was kept at a constant temperature under continuous agitation by a magnetic stirrer. The best combination will be chosen after undergoing further tests i.g. tensile testing, microwave testing and water absorption properties. Furthermore, the thicknesses were measured in eight places using a digital micrometer (Accu Remote, Model, Manufacturer, City and State, USA). In order to get representative result, fourteen replicates were measured for each film and the average values were reported based on Syima and Shahid [38] research.

\section{Mechanical testing}

The mechanical properties (hardness test) of the developed plastic sheet will be determined according to Standard Test Method for Tensile Properties of Plastics ASTM standard method D785-03 (ASTM, 2012). A Perten TVT 300-XPH (Perten, Hagersten, Sweden) texture analyser equipped with a $5 \mathrm{~kg}$ load cell will be used to conduct textural analyses [39]. The maximum force and distance at the break point were determined automatically by a software texture analyzer. All samples were cut into rectangular strips $10 \mathrm{~mm}$ wide and $60 \mathrm{~mm}$ long, after conditioning at $50 \pm 1 \%$ relative humidity (RH) for $24 \mathrm{~h}$. The samples strips were set with grip separation $(40 \mathrm{~mm})$ and stretched at a crosshead speed of $0.6 \mathrm{~mm} / \mathrm{s}$. 


\section{Microwave testing}

The microwave response of samples was studied by using household microwave oven (MS2041F, LG, Yeongdeungpo-gu, Seoul, South Korea). The specimen was prepared and then placed in the microwave oven at testing condition at 700 watt for 1 and $1.5 \mathrm{~min}$. After complete testing, the specimen was taken out from the oven and immediately measured the temperature on the surface. The physical changing of specimen was also recorded. As a comparison, same test was conducted with submerging treatment in the water. Four duplicates of each sample were repeatedly tested and the mean temperature was reported [40].

\section{Water absorption properties}

The water absorption of the film will be conducted according to ISO standards 62 : 2008. The percentage of water absorption is calculated according to the following equation:

$$
W A \%=\frac{W 2-W 1}{W 1} \cdot 100 \%
$$

where W1 is the weight of oven-dried composite sample before immersion and W2 is the weight of the composite sample after immersion.

The period of immersion is at the $30 \pm 2 \mathrm{~min}$, and then specimens were removed from the boiling water and cooled in distilled water at room temperature. Subsequently, after 16 min, the specimens were removed from the water, and all surface water was detached with a tissue paper. The water content was weighed within an interval of $30 \pm 2 \mathrm{~min}$. After each of these intervals, the test specimens were removed from the water, cooled in distilled water, dried and measured. The results reported is the average of assessment [28].

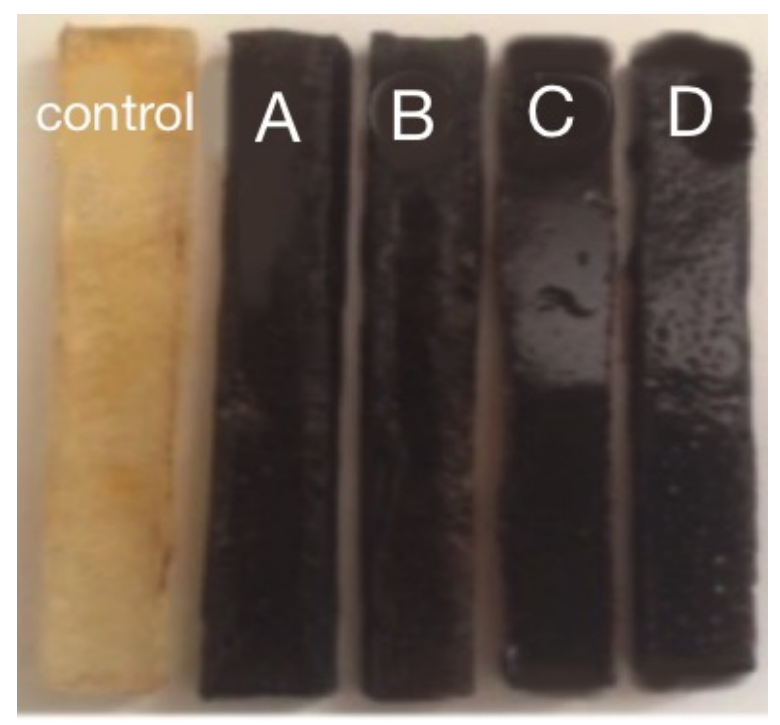

Figure. 3 Image of the sample made of nanosilica, SPW fiber and PLA combination A (60:20:20), B (70:20:10), C (70:10:20), D (65,15,15), Control (0:0:100). 


\section{Results and discussion}

\section{Mechanical property analysis}

According to Liou, Chang [41] method, and calculation, the silica content in carbonized RHA is approximately $50.15 \mathrm{wt} \%$. The effects of the SPW and Silica from RHA on mechanical properties of PLA composite sheets are demonstrated for the hardness strength, respectively, shown as shown in Figure 3. Four specimens of each formula were repeatedly tested and the average value was reported. In the average, sample A poses the highest strength $(\bar{x} 140.50 \mathrm{~N})$ compare to rest of the samples. Compared to the other samples, sample B shows the weakest structure $(\overline{\mathrm{x}} 62.37 \mathrm{~N})$.

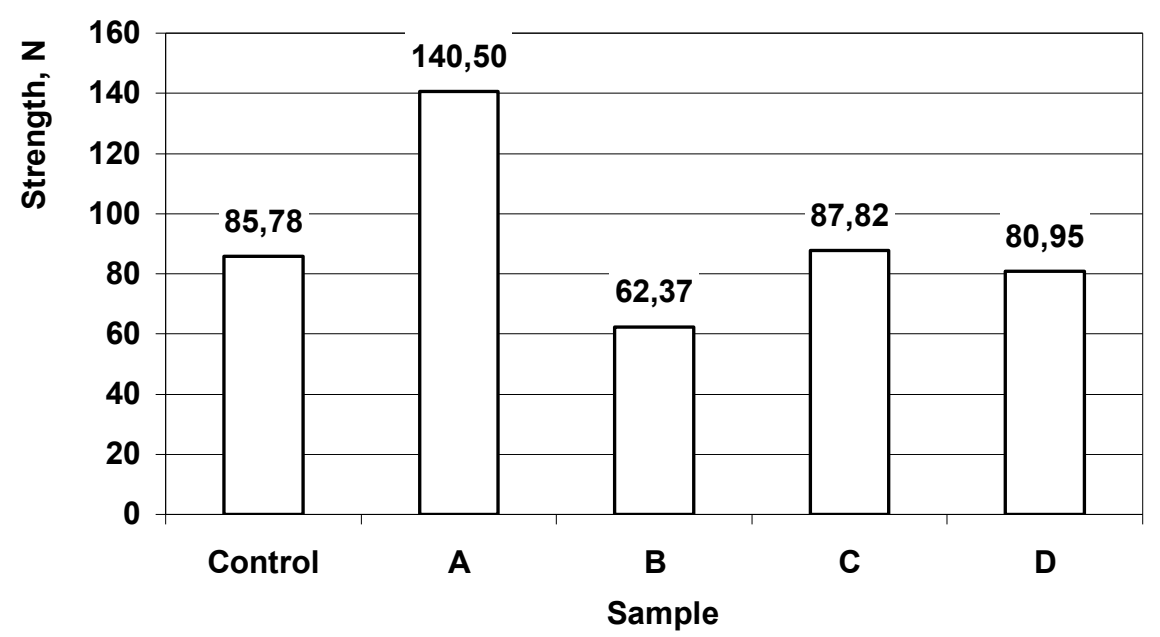

Figure 4. Average hardness results of 5 samples:

Control (SD 9.13), A (SD 1.96), B (SD 19.32), C (SD 20.49), D (SD 12.36)

Each polymers naturally has specific mechanical response when mixed with nanoparticles composite particularly their strength and elasticity of its component. The results showed that nanosilica (nano-SiO) and fiber embedded in PLA matrix at the certain comparison has shown improvement of mechanical properties, particularly in hardness compared to PLA itself. According to Liou and Yang [37], the nanosilica was produced from alkali-extracted rice husk ash and has a uniform size of 5-30 nm particle which dispersed in PLA matrix. The benefit of nanosize material of the silica result in larger surface area/ unit volume which strongly affect the chemical and physical interaction of the polymer, hence the application in the packaging industry would benefit the reliability of the combination materials [42-44]. The sample A (consists of $20 \%$ of nanosilica and SPW fiber) demonstrates the effective of PLA combination tailored with the fillers and indicated the strongest sample from the rests. The sample becomes more rigid and sturdy due to crosslinking interphase in the composites in comparison with control and the rest of the sample $[45,46]$. 


\section{Microwavability of modified PLA}

The microwave response of PLA samples in microwave oven at various conditions treatment were showed in the Figure 5.

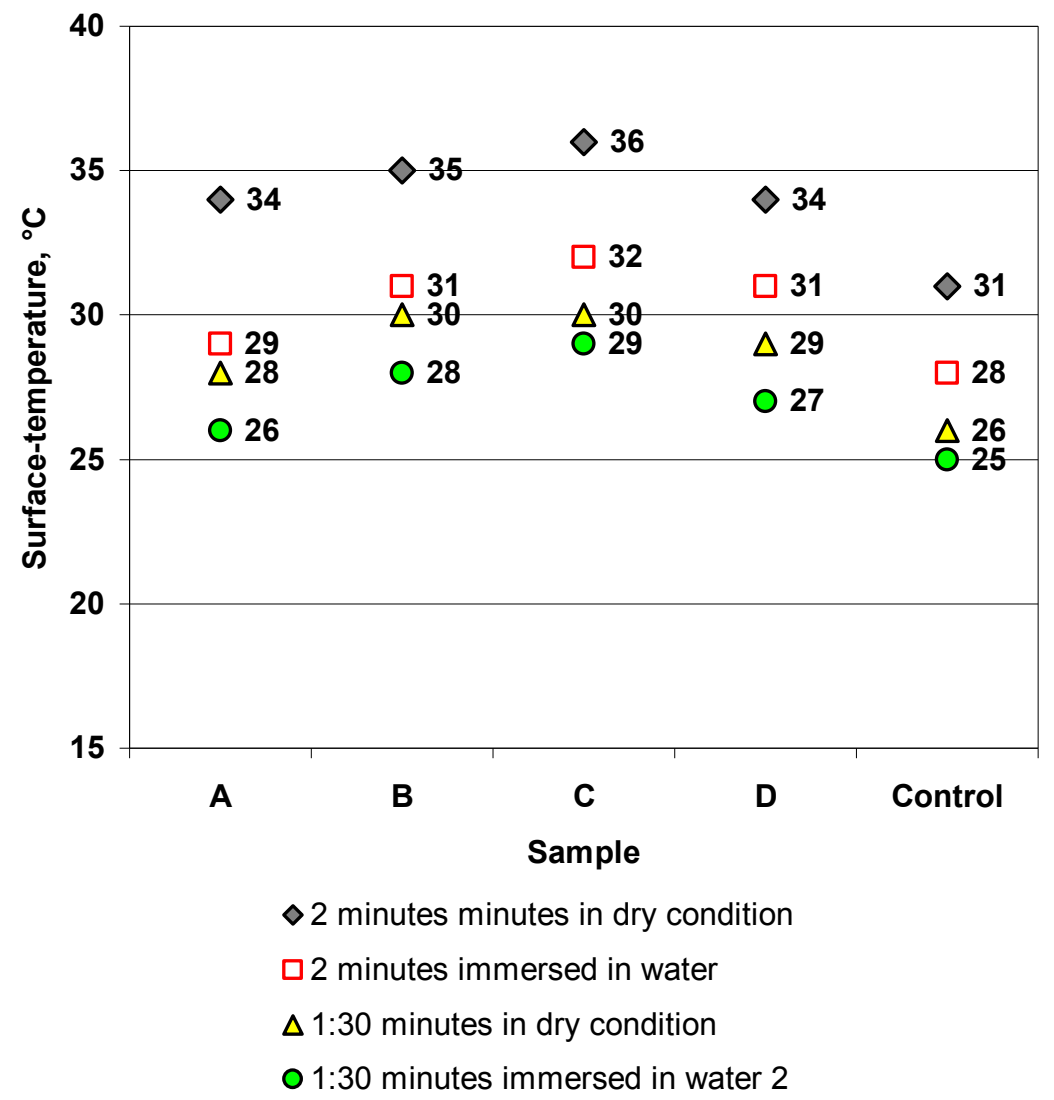

Figure 5. The average surface-temperature of control, sample A, B, C, and D at various settings in the microwave power 700 Watt

The surface temperature was measured to present the PLA response towards microwave exposure. Comparing between two condition i.e dry and immersed in water, it can be seen that all modified PLA samples have higher temperature than pure PLA sample. In 2 minutes dry condition the control showed $31^{\circ} \mathrm{C}$ on average, while on average, the rest of the sample, A, B, C, and D showed higher temperature $\left(33,35,36\right.$, and $34{ }^{\circ} \mathrm{C}$ respectively). Similar trends also showed in 2 minutes immersed in water, 1.30 minutes in dry condition and 1.30 minutes in water. The mean of sample $\mathrm{C}$ indicated the highest value of all sample in four categories $\left(\overline{\mathrm{x}}=36,32,30\right.$, and $29^{\circ} \mathrm{C}$ respectively). This might have been caused by the nanosilica composite exhibited an excellent thermal insulation and slow thermal desorption during thermal exposure be accumulated in the polymer matrix and result to higher temperature among modified and pure PLA [47, 48]. 
The graph also showed that, the pattern of the wave exposure showed that the higher density of matrix especially nanosilica the lower temperature reached by the sample surfaces. These trends were similar for both sample conditions, in dry and immersed in water. The crosslinked structure of the filler with the matrix (PLA) in this case nanosilica and SPW fiber as a hybrid filler, reduced space for polymer molecules to move during microwave radiation. Furthermore, compared to dry condition, in immersed water condition sample showed lower temperature. This response was caused by water in vapor form absorb more energy than filler itself and has lower ability to release heat that in liquid the form $[22,23,49]$.

\section{Water absorption behaviour}

Besides mechanical and effect of microwave towards PLA properties, water absorption is another critical consideration for plastic packaging. This factor is useful to measure durability of the sample against various treatments especially when washing and submerged in water. The results of water absorption of composites after boiling in distilled water with different percentage of nanosilica and SPW fiber loading are shown in table 2.

Water absorption of PLA formula

Table 2

\begin{tabular}{|c|c|c|c|c|}
\hline Sample & $\begin{array}{c}\text { Mean weight before } \\
\text { treatment (g) }\end{array}$ & $\begin{array}{c}\text { Standard } \\
\text { deviation } \\
\text { (SD) }\end{array}$ & $\begin{array}{c}\text { Mean weight after } \\
\text { treatment (g) }\end{array}$ & $\begin{array}{c}\text { Standard } \\
\text { deviation }\end{array}$ \\
\hline Control & 3.88 & 0.04 & 3.95 & 0.03 \\
\hline $\mathrm{A}$ & 3.11 & 0.14 & 3.15 & 0.15 \\
\hline $\mathrm{B}$ & 2.46 & 0.19 & 2.69 & 0.07 \\
\hline $\mathrm{C}$ & 3.16 & 0.24 & 3.26 & 0.24 \\
\hline $\mathrm{D}$ & 3.22 & 0.06 & 3.27 & 0.06 \\
\hline
\end{tabular}

In daily application such as, as a food container high water absorption can be significantly reduced by adding low molecular weight compounds such as triethyl citrate, glycerol, sorbitol, and ethylene glycol $[50,51]$. The water penetrability of modified PLA can be a source of material degradation. The water remaining in the matrix can be utilized by microorganism to grow, which could contaminate food items. Due to PLA price relatively costly, combination with natural fiber exhibits advantages such as tensile strength and tensile modulus increased yet with a slight decline in the elongation compared with pure PLA [52, 53].

In this experiment, each sample shows vary percentage weight after measurement; the mean of water absorbed for sample A, B, C, D, E are 1.55\%; $0.96 \% ; 1.89 \% ; 2.85 \% ; 3.12 \%$ respectively. It can be observed , as a control, sample A absorbed more water compare to all samples whereas sample B shows the lowest percentage of all. Sample B indicated the hydrophobicity of modified PLA. Sample B contains more silica than fiber (20:10) in the matrix that increases the brittleness of the PLA sample blend. Combination of nanosilica sample decreases the water uptake of modified composites compared to control/pure compound. This occurred due to the convoluted barrier built by nanosilica inhibited water molecule to penetrate into PLA sample composite $[54,55]$. 
The high possibility further development of this hybrid material is potentially used as substitution of one time use food and beverages container such as processed instant food, raw food from supermarkets (meat, vegetables, fruits, etc), ready to eat food and beverages from shops or drive through food stalls (ice cream, juice, tea, coffee, etc). Globally, reported from world packaging organisation, plastic packaging, derived from petroleum, was the second largest waste under paper and cardboard for packaging [56]. Whereas container made of polystyrene foam causes environmental and health issues. Several cities in the USA for instance Seattle, New York's Glen Cove, Massachusetts' Brookline, Boston, Amherst and in Hawaii [57, 58].

After doing three experiments, this hybrid combination has been shown high potential for replacing function of conventional plastic and Styrofoam as a food packaging. As a bio filler, the material reduced the use of plasticizer agent that directly minimise the production cost in the industrial scale. Furthermore, the use of SPW and RHA significantly contribute to decrease this agricultural waste at the same time increase the economical value of the materials. The results showed the proper combination of material generated high density and strength more than control (PLA itself). While microwavability and water absorption test show insignificant changes of behaviour compared to the control sample. Hence, the formula combination SPW and RHA with PLA showed strong possibility to be applied as eco friendly packaging for specially for one time use food container.

\section{Conclusion}

The plastic sheet test result indicated the potential usage of nanosilica and SPW fiber from agricultural waste. We directly reduce the agricultural waste and turn it into ecofriendly plastic sheet as the basic form of food container development. The main characteristic of this sample is reach the sturdy level of oil based/conventional plastic, less water absorbtion, and stable in the microwave and heat. In the experiment, slight changes in the temperature of a modified hybrid-filler sample indicated that the sample was remained stable for both condition. Hence, when the sample applied into food packaging, whether in wet or high temperature condition, the packaging has no effect to the food or beverages. Furthermore, this study examined the effect of nanosilica and SPW fiber as hybrid agent on the physical and mechanical properties of PLA. The crosslinking of the hybrid filler with the PLA matrix effectively improves hardness properties in PLA with combination 60:40 (filler) an is also the key of stability during the tests. In this experiment we found insignificant temperature changes of the modified sample with hybrid filler both in wet and dry condition than the neat PLA samples as the majority of the sample is still PLA itself. Additionally, the higher density of matrix especially nanosilica, the lower temperature reached by the sample surfaces due to smaller space for molecule movement. Combination of nanosilica sample (PLA: nano silica: SPW fiber; 70:20:10) optimally decreases the water uptake compared to control/pure PLA. The complex barrier built by nanosilica and SPW fibre inhibited water molecule to infiltrate into modified PLA sample. The future development of this material is potentially substitute one time use food and beverages container derived from petroleum and made of polystyrene foam that cause environmental and health issues.

Acknowledgements. The authors would like to thank all the wonderful staffs and post-graduate students at building 400 and hub 101, School of Public Health, Curtin University. Our high appreciation for the support and assistance of laboratory staffs (Ms Nerissa Ho, Dr. Syed Abbas, Amy Ward, Liliana Rejon Torres, Mr Edwin Junaldi and Dr. Mala Senaratna) in the School of Public Health, Curtin University. 


\section{References}

1. Jabeen N., et al. (2015), Bioplastics and food packaging: A review, Cogent Food \& Agriculture, 1(1), pp. 1117749.

2. Sanchez-Garcia M., J. Lagaron, and S. Hoa (2010), Effect of addition of carbon nanofibers and carbon nanotubes on properties of thermoplastic biopolymers, Composites science and technology, 70(7), pp. 1095-1105.

3. Avella M., et al. (2005), Biodegradable starch/clay nanocomposite films for food packaging applications, Food chemistry, 93(3), pp. 467-474.

4. Muthayya S., et al. (2014), An overview of global rice production, supply, trade, and consumption, Annals of the New York Academy of Sciences, 1324(1), pp. 7-14.

5. Thuc C.N.H. and H.H. Thuc (2013), Synthesis of silica nanoparticles from Vietnamese rice husk by sol-gel method, Nanoscale research letters, 8(1), pp. 1.

6. Della V.P., I. Kühn, and D. Hotza (2002), Rice husk ash as an alternate source for active silica production, Materials Letters, 57(4), pp. 818-821.

7. Chandrasekhar S. (2003), et al., Review Processing, properties and applications of reactive silica from rice husk - an overview, Journal of Materials Science, 38(15), pp. 3159-3168.

8. Sindoro M., et al. (2013), Colloidal-sized metal-organic frameworks: synthesis and applications, Accounts of chemical research, 47(2), pp. 459-469.

9. Paulsamy M. (2018), et al., Nepafenac loaded silica nanoparticles dispersed in-situ gel systems: Development and Characterization, International Journal of Biological Macromolecules.

10. Zaky R.R., et al. (2008), Preparation of silica nanoparticles from semi-burned rice straw ash, Powder Technology, 185(1), pp. 31-35.

11. Abral H., et al. (2013), Effect of Alkalization on Mechanical Properties of Water Hyacinth Fibers-Unsaturated Polyester Composites, Polymer-Plastics Technology and Engineering, 52(5), pp. 446-451.

12. Arribas, A., et al. (2009), Scratch resistance of a polycarbonate+ organoclay nanohybrid, Express Polymer Letters, 3, pp. 621-629.

13. Chujo Y. (2007), Organic - Inorganic Nano-Hybrid Materials [Translated]. KONA Powder and Particle Journal, 25, pp. 255-260.

14. Sellinger A., et al. (1998), Continuous self-assembly of organic-inorganic nanocomposite coatings that mimic nacre, Nature, 394(6690), pp. 256-260.

15. Gröger, C., K. Lutz, and E. Brunner (2008.), Biomolecular Self-assembly and its Relevance in Silica Biomineralization, Cell Biochemistry and Biophysics, 50(1), pp. 23-39.

16. Han J., et al. (2015), Characterization of physical, mechanical, and antioxidant properties of soy protein-based bioplastic films containing carboxymethylcellulose and catechin, Food Science and Biotechnology, 24(3), pp. 939-945.

17. Šuput D.Z., et al. (2015), Edible films and coatings: Sources, properties and application, Food and Feed Research, 42(1), pp. 11-22.

18. Sánchez-Ortega, I., et al. (2014), Antimicrobial edible films and coatings for meat and meat products preservation. The Scientific World Journal.

19. Brockhaus, S., M. Petersen, and W. Kersten (2016), A crossroads for bioplastics: exploring product developers' challenges to move beyond petroleum-based plastics, Journal of Cleaner Production, 127, pp. 84-95. 


\section{- Food Technology}

20. Huba A.K., K. Huba, and P.R. Gardinali (2016), Understanding the atmospheric pressure ionization of petroleum components: The effects of size, structure, and presence of heteroatoms, Science of The Total Environment, 568, pp. 1018-1025.

21. Pelisser, F., et al. (2010), Effect of the addition of synthetic fibers to concrete thin slabs on plastic shrinkage cracking, Construction and Building Materials, 24(11), pp. 21712176.

22. Bott J., A. Störmer, and R. Franz (2014), Migration of nanoparticles from plastic packaging materials containing carbon black into foodstuffs, Food Additives \& Contaminants: Part A, 31(10), pp. 1769-1782.

23. Briassoulis D., et al. (2014), Design of a European agrochemical plastic packaging waste management scheme - Pilot implementation in Greece. Resources, Conservation and Recycling, 87, pp. 72-88.

24. Cherif Lahimer M., et al. (2013), Characterization of plastic packaging additives: Food contact, stability and toxicity, Arabian Journal of Chemistry.

25. Rochman C.M. (2015,), The Complex Mixture, Fate and Toxicity of Chemicals Associated with Plastic Debris in the Marine Environment, in: Marine Anthropogenic Litter, M. Bergmann, L. Gutow, and M. Klages, Springer International Publishing: Cham., pp. 117-140.

26. Hammer J., M.H.S. Kraak, and J.R. Parsons (2012,), Plastics in the Marine Environment: The Dark Side of a Modern Gift, in: Reviews of Environmental Contamination and Toxicology, M.D. Whitacre, Springer New York: New York, NY. pp. $1-44$.

27. Rahmatiah Al Faruqy, M.S. and K.C. Liew (2016), Properties of Bioplastic Sheets Made from Different Types of Starch Incorporated With Recycled Newspaper Pulp.

28. Li X., et al. (2014), The utilization of bamboo charcoal enhances wood plastic composites with excellent mechanical and thermal properties, Materials \& Design, 53, pp. $419-424$.

29. Danks A.E., S.R. Hall, and Z. Schnepp (2016), The evolution of 'sol-gel' chemistry as a technique for materials synthesis, Materials Horizons, 3(2), pp. 91-112.

30. Ramakrishnan K., et al. (2008), Modern aerogels, 27.

31. Adam F., T.-S. Chew, and J. Andas (2011), A simple template-free sol-gel synthesis of spherical nanosilica from agricultural biomass, Journal of Sol-Gel Science and Technology, 59(3), pp. 580-583.

32. Lofgreen J.E. and G.A. Ozin (2014), Controlling morphology and porosity to improve performance of molecularly imprinted sol-gel silica, Chemical Society Reviews, 43(3), pp. $911-933$.

33. Dave B.C. (2016), Sol-Gel Coating Methods in Biomedical Systems, Medical Coatings and Deposition Technologies, pp. 373.

34. López T.M., D. Avnir, and M.A. Aegerter (2013), Emerging fields in sol-gel science and technology, Springer Science \& Business Media.

35. Supranto S. (2013), Optimization of the High Refined Cellulose process production from theSago Fiber Waste by a delignification process involving nitric acid, sodiumhydroxide and hydrogen peroxide as the delignificating agent.

36. Supratno S., A. Tawfiequrrahman, and D. Yunanto (2014), Sugarcane Bagasse Conversion to High Refined Cellulose using Nitric Acid, Sodium Hydroxide and Hydrogen Peroxide as the Delignificating agents, Proceeding of the 27th Regional Symposium on Chemical Engineering. 
37. Liou T.-H. and C.-C. Yang (2011), Synthesis and surface characteristics of nanosilica produced from alkali-extracted rice husk ash, Materials science and engineering: $B$, 176(7), pp. 521-529.

38. Syima N. and M. Shahid (2016), Antimicrobial Efficacy of Biodegradable Films and Coatings on Beef, School of Public Health, Curtin University, pp. 195.

39. Haubjerg A., et al. (2013), Rheological properties as indicator for physico-chemical processes affecting technical quality of extruded fish feed.

40. Saengiet B., et al (2012), Response of Modified Poly (lactic acid) to Microwave Radiation, Advanced Materials Research, Trans Tech Publ.

41. Liou T.-H., F.-W. Chang, and J.-J. Lo (1997), Pyrolysis kinetics of acid-leached rice husk, Industrial \& engineering chemistry research, 36(3), pp. 568-573.

42. Khan S.B., et al. (2011), Synthesis and characterization of novel PPC-silica hybrid with improved thermal, mechanical, and water sorption properties, Macromolecular research, 19(9), pp. 876.

43. Luo J.-J. and I.M. Daniel (2003), Characterization and modeling of mechanical behavior of polymer/clay nanocomposites, Composites science and technology, 63(11), pp. 1607-1616.

44. Pavlidou S. and C. Papaspyrides (2008), A review on polymer-layered silicate nanocomposites, Progress in polymer science, 33(12), pp. 1119-1198.

45. Frone A.N., et al. (2013), Morphology and thermal properties of PLA-cellulose nanofibers composites, Carbohydrate Polymers, 91(1), pp. 377-384.

46. Karger-Kocsis J., H. Mahmood, and A. Pegoretti (2015), Recent advances in fiber/matrix interphase engineering for polymer composites, Progress in Materials Science, 73, pp. 1-43.

47. Arthur C.L. and J. Pawliszyn (1990), Solid phase microextraction with thermal desorption using fused silica optical fibers, Analytical Chemistry, 62(19), pp. 21452148.

48. Shi S., J. Liang, and R. He (2015), Thermal decomposition behavior of silica - phenolic composite exposed to one-sided radiant heating, Polymer Composites, 36(8), pp. 1557-1564.

49. Bledzki A., S. Reihmane, and J. Gassan (1998), Thermoplastics reinforced with wood fillers: a literature review, Polym.-Plast. Technol. Eng., 37(4), pp. 451-468.

50. Snejdrova E. and M. Dittrich (2012), Pharmaceutically used plasticizers, Recent advances in plasticizers., InTech.

51. Ugelstad J., et al. (1979), Absorption of low molecular weight compounds in aqueous dispersions of polymer - oligomer particles, 2. A two step swelling process of polymer particles giving an enormous increase in absorption capacity, Macromolecular Chemistry and Physics, 180(3), pp. 737-744.

52. Wambua P., J. Ivens, and I. Verpoest (2003), Natural fibres: can they replace glass in fibre reinforced plastics?, Composites Science and Technology, 63(9), pp. 1259-1264.

53. $\mathrm{Ku} \mathrm{H}$., et al. (2011), A review on the tensile properties of natural fiber reinforced polymer composites, Composites Part B: Engineering, 42(4), pp. 856-873.

54. Becker O., R.J. Varley, and G.P. Simon (2004), Thermal stability and water uptake of high performance epoxy layered silicate nanocomposites. European Polymer Journal, 40(1), pp. 187-195.

55. Zhao H. and R.K. Li (2008), Effect of water absorption on the mechanical and dielectric properties of nano-alumina filled epoxy nanocomposites, Composites Part A: Applied Science and Manufacturing, 39(4), pp. 602-611. 
56. Pearson K. (2008), Market statistics and future trends in global packaging. Report, Available at: http://www.worldpackaging.org/publications/documents/marketstatistics.pdf.

57. Koch W. (2012), Cities ban foam coffee cups and takeout containers, Available at: https://www.usatoday.com/story/news/nation/2012/12/12/ban-polystyrene-foamcontainers/1761145/.

58. White G. (2008), The Case for Banning Styrofoam Foodservice Ware in Hawaii. 